\title{
ESCRIBIENDO CON EL ENEMIGO: LENGUAJE, PERIODISMO Y DEMOCRACIA*
}

\section{Ascanio Cavallo}

\begin{abstract}
RESUMEN: En esta conferencia, el autor indaga, a través de un diálogo ficticio pero posible, la posibilidad de un lenguaje democrático para el periodismo. Las preguntas, sin embargo, terminan por llevarlo más lejos, para enfrentar la doble naturaleza del lenguaje: una fuerza redentora innegable, por un lado, y una herramienta del mal, por el otro. PALABRAS ClAVE: periodismo, lenguaje, democracia, dictadura militar, totalitarismos, Guillermo Blanco.
\end{abstract}

\section{WRITING WITH THE ENEMY: LANGUAGE, JOURNALISM AND DEMOCRACY}

ABSTRACT: At this conference, the author inquires, through fictitious yet plausible dialog, as to the possibility of a democratic language for journalism. However, the questions end up taking him further, to confronting the dual nature of language: an undeniable redeeming force, on the one hand, and a tool for evil, on the other.

KEYwords: journalism, language, democracy, military dictatorship, totalitarianism, Guillermo Blanco.

Ascanio Cavallo (Santiago de Chile, 1957). Periodista de la Universidad de Chile. Columnista político del diario La Tercera y crítico de cine de la revista Sábado de El Mercurio. Fue director del diario La Época y de la revista Hoy. Ex decano de la Escuela de Periodismo de la Universidad Adolfo Ibáñez y actual director de Tironi y Asociados. Entre sus muchos libros figuran La historia oculta del régimen militar, con Manuel Salazar y Óscar Sepúlveda (1988); Cien claves del cine, con Antonio Martínez (1995) y La historia oculta de la transición (1998). Email: ascanio.cavallo@ tironiasociados.com

* Versión corregida de la conferencia dada por el autor el 2 de septiembre de 2014, al incorporarse como miembro de número a la Academia Chilena de la Lengua. 
ste es uno de los días más misteriosos que me hayan sido depa-
rados. Vengo a incorporarme como miembro de número de esta ilustre academia, el honor más alto que puede recibir un periodista que en la mayor parte de su carrera ha trabajado con la lengua escrita. Me recibe un amigo, Abraham Santibáñez, al que conozco hace casi cuarenta años y al que por todo ese tiempo no he dejado de considerar uno de mis maestros. Y vengo a ocupar el sillón que dejó vacante otro amigo, Guillermo Blanco, a quien también estimé como a un maestro.

El destino es extraño. O es un conjunto azaroso de acontecimientos que siguen el principio del caos, o es una cadena de sucesos que se ordenan según alguna lógica secreta.

En la segunda mitad de 1978, después de un par de intentos frustrantes por emprender una práctica profesional decorosa, fui a pedir auxilio a quien había sido mi profesor de política internacional en la Universidad de Chile. Abraham Santibáñez era entonces el subdirector de la revista Hoy, que desde su creación en 1977 se había convertido en el sueño de los estudiantes de periodismo, un parnaso donde se reunían los mejores profesionales jóvenes de entonces.

Con la silenciosa generosidad que es su marca de estilo, Abraham Santibáñez me comunicó unos días después que podría ingresar como practicante en la sección Cultura, que a su turno era el sueño de los estudiantes pretenciosos. El editor era Guillermo Blanco. Tenía a su cargo a una sola redactora, Irene Bronfman, quien después ha sido mi gran amiga de toda la vida. Y tenía una montaña de crónicas despachadas por correo desde todos los puntos del orbe a donde el exilio había enviado a una gran cantidad de periodistas notables.

Esa montaña fue mi primera misión. Con cualquier otra persona habría sido una cosa sencilla: ordenar, pulir, retocar y ya. A Guillermo Blanco había, además, que convencerlo. Es decir, había que convencer a quien, además de jefe, era ya un tótem de la literatura chilena, un autor al que venía leyendo desde la enseñanza básica y cuya prosa templada me había cautivado muchos años atrás, en una difícil lucha contra la prosa estilosa de Julio Cortázar y la prosa impresionante de Mario Vargas Llosa, con quienes compartía su pasión por el drama pasado, presente y continuo de América Latina.

No era sólo él. Guillermo Blanco participaba de un grupo profesional, el de la revista Hoy, con una aguda conciencia del lenguaje como 
herramienta y como problema. Lo acompañaban en eso grandes redactores, como Emilio Filippi, Abraham Santibáñez, Hernán Millas, María Paz del Río, Jaime Moreno Laval, Ignacio González Camus, Mónica Blanco, Juan Andrés Piña, Manuel Délano, Antonio Martínez y muchos otros, un equipo cuya atención por el idioma no he visto en ningún otro medio periodístico. Me hubiese gustado hablar de esas personas y en especial de Emilio Filippi, quien dirigió Hoy y más tarde La Época, donde cometió la audacia de entregar el proyecto y el manejo de ese diario a un grupo de "jóvenes turcos", entre los cuales tuve el honor de contarme.

Pero la síntesis y la tradición me circunscriben a mi antecesor en el asiento que ocuparé. Sólo que estas palabras no contendrán el homenaje usual, sino que ese homenaje será su desarrollo.

Por aquellos días, Guillermo Blanco ya había iniciado su investigación sobre Miguel de Unamuno, que 25 años más tarde se convertiría en el libro El león sin sus gafas. ${ }^{1}$ Su centro era ese dramático incidente en el Paraninfo de Salamanca, el 12 de octubre de 1936, cuando el ya veterano don Miguel, que había apoyado el alzamiento de Franco contra la República, se enfrentó al general Millán-Astray, héroe de guerra, luego de oírlo gritar dentro de la universidad la consigna de su legión: "¡Viva la muerte!".

No quiero reducir el interés de Guillermo Blanco por Unamuno a un incidente político, aunque éste fue el último antes de que el año 1936 y la España desangrada terminaran con su vida. Pero vivíamos en una situación que nos parecía similar. La violencia y el odio se habían instalado en Chile como si este país hubiese sido su hogar. La nación estaba quebrada entre vencedores y vencidos. Las persecuciones adquirían las formas repetidas de la exclusión o la crueldad. Un lenguaje de descalificación y aniquilamiento invadía el espacio público. Nuestras universidades estaban ocupadas por oficiales militares y no costaba imaginar a Millán-Astray en cualquiera de sus claustros.

En una época oscura de su nación, medio siglo antes que nosotros, el profesor Unamuno, viejo, solo, desarmado, había tenido que buscar, de manera desesperada y urgente, algún lenguaje para hacer frente a otro lenguaje, el del fascismo, que arrancaba aplausos y elogios de oportunidad entre sus propios colegas.

${ }^{1}$ Guillermo Blanco, El león sin sus gafas (Santiago: Editorial Andrés Bello, 2003). 
La historia de Unamuno nos planteaba a todos - a los maestros y a nosotros, los debutantes - el problema de cómo decir y cómo escribir en medio de la violencia.

Hasta aquí llegan mis recuerdos fidedignos. Con el tiempo he llegado a dudar de que algunas de las conversaciones con Guillermo Blanco que creo recordar hayan ocurrido realmente. Me he encontrado a veces expandiendo los dos años en que trabajamos juntos más allá de toda realidad posible, y hasta puedo imaginar que ese diálogo se haya extendido como un rumor, bajo el pavimento, bajo la noche, bajo la muerte, por mucho tiempo después.

-En Salamanca — comenzó el Uno-, Unamuno respondió al general Millán-Astray con una profecía: "Venceréis, pero no convenceréis". La fuerza no superará a la razón.

- Gran idea idealista — dijo el Otro, en plan burlesco-. Pasaron cuarenta años antes de que fuese confirmada. Pero recuerda que aquel mismo día Unamuno agregó unas cosas feroces acerca de la condición del general: "símbolo de la muerte", "inválido", "mutilado". Aunque es difícil juzgarlo ahora, creo que no eran las palabras justas. Demasiada ira, demasiada rabia convertida en agresión personal. No calza con su apelación a la razón.

-Es un buen punto - respondió el Uno-. Que nos lleva al problema del decir en medio de la violencia.

— ¿Te parece — preguntó el Otro- que realmente haya algo diferente en decir o escribir en la violencia? ¿Dónde puede estar lo distintivo, si siempre que se escribe se trabaja con un instrumento elusivo, polisémico, por decir lo menos inestable? La escritura podrá ser privada, secreta, incluso clandestina. ¿Pero se podrá decir lo mismo a propósito de, por ejemplo, el periodismo, que debe estar más atento a la claridad y a la eficacia?

-Es cierto - dijo el Uno-. Pero la verdadera pregunta es la inversa: ¿es posible que la violencia, con su fuerza invasiva, no afecte al problema de la palabra pública? Peor aún, ¿podrían ignorarlo quienes están expuestos día por día a la amenaza de la censura o el silenciamiento violento? El que escribe bajo esas condiciones no puede escribir como sus opresores. No puede hablar como ellos. Necesita hallar otro lenguaje.

- Lo dices - comentó el Otro- como si no fuese una interrogación política, ni siquiera moral, sino un problema profesional. 
—Claro — dijo el Uno-. ¿No es el periodismo una función de la democracia? Llámalo una condición, llámalo una excrecencia si prefieres.

- O sea que — se apuró el Otro - sería necesario que su lenguaje fuese democrático, o al menos que reflejase los valores, los modales, el talante, las condiciones de la conducta democrática. Un lenguaje antifascista o, para ser más amplios, antiautoritario.

- Y para eso lo primero - dijo el Uno, con una sonrisa - sería no creer que alguien, incluso uno mismo, es el dueño de toda la verdad. Nullius in verba, "de nadie en su palabra", recomendó Horacio, quien pensaba en los filósofos pero en realidad hablaba a los periodistas. ${ }^{2}$

- Supongo — se inquietó el Otro- que aquí no distinguimos ideologías.

-Desde luego - dijo el Uno, enderezando el cuello como si fuese a enunciar un desafío-, e incluso con conciencia de que siempre hay residuos ideológicos en el lenguaje, así como toda ideología se construye sobre el lenguaje. La dialéctica entre lenguaje e ideología, regulada por el principio de la tolerancia, puede ser fecunda. No hablo de eso. Me sitúo mucho antes, en la contradicción esencial entre democracia y dominación, y la forma en que ella se materializa en el lenguaje.

—Ah, eso sí — se entusiasmó el Otro, con ganas de ser elocuente- Los regímenes totalitarios siempre son más sensibles a este problema. Conocemos el control del hierro sobre el lenguaje escrito y audiovisual en los regímenes soviético y nazi, los remedos de prensa que han sido los boletines oficiales en Cuba y Corea del Norte, la penosa historia de la "revolución cultural" en la China de Mao, el aplastamiento de toda discrepancia en los medios bajo control islámico en Afganistán y así, ad nauseam, casos en que la represión de los medios fue siempre acompañada por la persecución de los artistas, los escritores y los intelectuales. Corrijamos al pastor Martin Niemöller, ¿te acuerdas?: "Primero vinieron a buscar a los comunistas...". Digamos: "Primero vinieron a buscar a los periodistas...". Toda la historia de los experimentos antidemocráticos del siglo XX muestra la pertinacia de ese patrón, un largo repertorio de censura, manipulación y amenaza.

-Eso es — dijo el Uno- Pero tu descripción queda incompleta si no agregas que en muchos de esos casos, si no en todos, el deterioro del

\footnotetext{
${ }^{2}$ Horacio, Epístolas. Libros Iy II (México: UNAM, 1986).
} 
lenguaje público precedió a la imposición dictatorial. La degradación de ese lenguaje, que es el de los medios de comunicación, ha sido con frecuencia el anticipo y el síntoma de la descomposición social. No tienes que ir muy lejos: mira el papel de los medios en la equívoca Primavera Árabe, mira el estallido del Maidan, fíjate en la conducta del Isis.

El Uno se detuvo un momento, como si lo inundase una ola de recuerdos. Siguió:

-En Chile vivimos ese fenómeno. Primero con sorpresa, después con una curiosidad desaprensiva y más tarde con el dolor de las desgracias. En sólo un par de años pasamos del titular de un diario de izquierda que calificaba a los ministros de la Corte Suprema como "viejos de mierda" al titular de un diario de derecha que describía una masacre con una frase de escalofrío: "Miristas se matan como ratas". La prensa chilena de los setenta contribuyó a la tragedia nacional casi tanto como los grupos armados, los partidos, la policía y la justicia, aunque siempre se percibió a sí misma a la zaga de la convulsión política. Por desgracia, ésta es una verdad ilusoria. Sin el idioma del incendio, la devastación y la intolerancia, el país no habría entendido, como lo hizo, que todo lo que estaba ocurriendo era normal y anodino; no habría continuado con el insensato rumbo al precipicio. Por lo menos, lo habría pensado algo más.

—El lenguaje del odio — pensó el Otro, con voz apenas audibleOrwell identifica el poder político del odio cuando hace que los habitantes de Oceanía tengan esos inolvidables "dos minutos de odio" en 1984. ${ }^{3}$ Pero nadie lo ha descrito mejor que el "Che" Guevara en su discurso ante la Asamblea Tricontinental, en abril de 1967: "El odio convierte a un hombre en una máquina de matar". ${ }^{4}$ Él quería eso; máquinas de matar para crear uno, dos, muchos Vietnam.

-No parece que esos deseos hayan sido compartidos por los chilenos — comentó el Uno- Pero lo que ocurrió es que en este país decenas, quizás cientos de hombres corrientes fueron convertidos en "máquinas de matar" por la sola incitación al odio. "Tenemos que matar al odio", había advertido el cardenal Silva Henríquez, "antes de que el

\footnotetext{
${ }^{3}$ George Orwell, 1984 (Barcelona: Destino, 2009).

${ }^{4}$ Fernando Díaz Villanueva, Che Guevara, fraude o leyenda (Madrid: Dastin, 2010).
} 
odio envenene y mate el alma de Chile". ${ }^{5}$ Casi nadie entendió que se refería, sobre todo, al lenguaje, el lenguaje público.

-Es extraño - dijo el Otro- Hasta finales de los setenta, ese ambiente no había terminado de desaparecer de nuestros medios de comunicación, a pesar de que una parte de ellos había sido borrada de la escena por la fuerza.

- Bueno — recordó el Uno-, la revista Hoy no nació al margen de esa tragedia, sino con la voluntad de evitar su repetición. Yo no venía de la inocencia, sino de la posición de testigo y en ocasiones hasta participante. Conocí Vietnam a fines de los 60. Sabía lo que quería decir Vietnam.

-Así que los que estuvimos en esos días empezábamos a procesar la experiencia de comienzos de los setenta. Y entonces, ¿habría algo así como un lenguaje antifascista, antitotalitario, antidominación? ¿Habría un lenguaje para la democracia?

—Uf, qué problema — respondió el Uno, con cierto agobio- - Para ensayar esta respuesta hay que preguntarse primero qué es la democracia, al menos como condición intelectual, sin entrar en los debates de las ciencias políticas, que suelen referirse a las dimensiones prácticas de la democracia - mayorías, elecciones y normas - y a veces a las de la moral pública. Desde un punto de vista epistémico, no es lo mismo.

- Claro, la democracia no tiene por requisito ser racional - se apresuró a comentar el Otro- . Bobbio mostró que las decisiones públicas pueden ser tomadas con motivos emocionales o instintivos. ${ }^{6}$ Una de las imperfecciones lícitas de la democracia es que mientras su naturaleza apela a la racionalidad, su ejercicio puede ser dominado por los sentimientos.

—Bien — dijo el Uno-, pero sí es condición esencial que sea un estado intelectual definido por la tolerancia, o sea, una disposición a reconocer a los otros como iguales y legítimos, y a cambiar de opinión sin que eso constituya una apostasía. Así entendida, la democracia supone de manera inevitable un cuerpo de valores: la vida sobre la muerte, la paz sobre la violencia, la tolerancia sobre el sectarismo, y así por delante.

${ }^{5}$ Cardenal Raúl Silva Henríquez, "Hay que matar el odio. Funerales de don Edmundo Pérez Z”, 1971, http://www.cardenalsilva.cl/pdf/27_hay.pdf/

${ }^{6}$ Norberto Bobbio, El futuro de la democracia (Bogotá: Fondo de Cultura Económica, 1996). 
—Mira qué curioso — comentó el Otro-, tu definición es casi la misma del mejor crítico de cine que conozco, Robin Wood, quien hasta su muerte en 2009 sostuvo con firmeza que no hay estética sin ética, y que la ética del arte sólo puede tener en su centro al ser humano. ${ }^{7} \mathrm{La}$ ausencia de esa ética elimina el arte. Mira qué radical. Pero no te voy dar la lata con el cine... Ya sabes que es lo mío, y yo sé que no es lo de todos.

— Sigue, me interesa mucho — dijo el Uno, con vivacidad renovada.

- Bueno, Wood afirma que el cine, la literatura, el arte, es totalitario cuando elimina la ambigüedad (la ambivalencia, como la ha llamado Paolo Virno ${ }^{8}$ ), cuando te obliga a una sola mirada y no te permite elegir ni pensar por ti mismo. El cine no es fascista porque lo haya producido Mussolini, ni totalitario porque lo financiara Lenin, sino que se hace fascista o totalitario cuando es unilateral y abusivo. Da lo mismo si el artista es la execrada Leni Riefenstahl o el apreciado Sergei Eisenstein. Una de las películas más admiradas de la historia, El acorazado Potemkin, le parece a Wood un mero panfleto. Y va más lejos: rechaza a Kubrick porque su cine transluce un profundo desprecio por el ser humano. Tras ese desprecio divisa un fascismo fusi, líquido, diluido, "ordinario" como lo llamó un memorable documental soviético, ${ }^{9}$ o quizás un fascismo postmoderno. No puedo estar en desacuerdo con él: si no nos sostiene una moral humana, pro humana, humanista, ¿qué puede sostenernos...? Ya, hasta aquí no más llego. Los periodistas no somos artistas y sólo algunos fungimos de críticos de estética.

-No - dijo el Uno-, los periodistas se mueven, nos movemos, a una escala muchísimo más modesta. Y sin embargo, su impacto social inmediato no tiene parangón. ¿No sería una gran idea que adoptasen el tipo de pensamiento crítico que relaciona la estética con la ética? ¿O que se pudieran pensar al menos con el orgullo de los artistas?

- No creo - replicó el Otro- Prefiero la modestia. Mucho antes de que el periodismo existiera, San Agustín condenó a una de nuestras materias primas, la curiosidad social, como una forma de concupiscen-

${ }^{7}$ Robin Wood, Personal views (Detroit: Wayne State University Press, 2006).

8 Paolo Virno, Gramática de la multitud (Madrid: Traficantes de Sueños, 2003).

${ }^{9}$ Mijail Romm, Obyknovennyy fashizm, 1965. 
cia. ${ }^{10}$ Imagínate a San Agustín viendo nuestros noticiarios nocturnos, o inscrito en una cuenta de Twitter... Pero volvamos a lo nuestro. Aún no me dices si puede existir algo así como un lenguaje democrático. ¿Cumpliría con esas normas un cierto lenguaje neutral, deslavado, anodino, que lo evite todo, que huya del conflicto? Sería insufrible, ¿no te parece? "Políticamente correcto", es decir, acomodaticio, timorato, un poco hipócrita.

-No, no parece que la cosa sea tan simple — respondió el Uno-. El lenguaje es responsable de una enorme proporción de las bellezas que conocemos. ¿Por qué el periodismo tendría que renunciar a ellas? No veo la razón para no extremar el esfuerzo por un lenguaje que sea bello y verdadero y, por eso mismo, democrático. Como sugiere tu amigo Robin Wood, la belleza es un conjunto de valores, no es sólo una proporción áurea. Él le exige al cine, al arte, que no traicione esos valores. Quizás sería cosa de preguntarnos si somos fieles a ellos cada vez que escribimos.

—Eso suena voluntarista — replicó el Otro-. ¿No te parece más útil aceptar que el lenguaje tiene una capacidad maligna? El doctor Fernando Lolas ha recordado hace poco la admonición del cervantino perro Cipión: "Vete a la lengua, que en ella consisten los mayores daños de la humana vida". ${ }^{11} \mathrm{O}$ como les dice Vallejo a los niños de América: "La letra en que nació la pena". ${ }^{2}$

—Estoy de acuerdo — dijo el Uno- . Hay que admitir que el lenguaje comparte las potencias de creación y destrucción que definen a todas las obras humanas, la doble levadura de nuestra naturaleza.

- Quiero llevarte un poco más lejos — propuso el Otro-. Tengo la impresión de que nuestra idea del lenguaje se ha construido sobre las maneras más arcaicas de entender el mundo, un detritus de los sistemas religiosos y su necesidad de explicar el origen de las cosas.

-Es bueno que lo definas como una necesidad — puntualizó el Uno- La primera de todas las necesidades, diría yo, para no hundirse en el vacío.

\footnotetext{
${ }^{10}$ San Agustín, Confesiones (Madrid: Ediciones Ciudad Nueva, 2003).

${ }^{11}$ Fernando Lolas, "Unir y dividir. Sobre la lengua, la academia, la política", conferencia en la Academia Chilena de la Lengua, 21 de abril de 2014.

${ }^{12}$ César Vallejo, España, aparta de mí este cáliz (Madrid: Árdora Ediciones, 2013).
} 
-Bien. Pero cuando la traslada a nuestros días, Slavoj Žižek designa esa necesidad como "la tentación del sentido": el impulso de muchas personas para enfrentar los grandes problemas mediante explicaciones totalizantes y, por lo general, maniqueas. Žižek se refiere al ecologismo radical, reforzado en nuestros días por convicciones apocalípticas, como las del calentamiento global. ${ }^{13}$

- Sin embargo - dijo el Uno-, y ya que hablas de eso, el lenguaje también nos ha enseñado a amar la naturaleza. Hay dos amores allí: la materia y lo que la describe. ¿No te parece un valor extraordinario?

-Ya, pero mira - dijo el Otro, montándose en una pendiente más radical—: sin ánimo de herir tu catolicismo, creo que a esa misma tradición pertenece la frase más autoritaria de la historia: "Hágase la luz". Refleja una manera de entender la palabra, el verbo, como una fuerza capaz de dar origen a la realidad material en un sentido literal.

— Claro — replicó el Uno, con perfecta serenidad-, es parte de lo que llamaste necesidad de entender las cosas.

- Sí, pero pone al verbo antes que al hombre — siguió el OtroConvierte a la palabra en algo más sagrado que la conciencia que la concibe. Invierte el orden de las cosas y entrega el poder a los administradores de la palabra. El lado satánico de lo divino.

- No exageres — respondió el Uno- . Fue la necesidad primordial, muchos siglos antes de que dispusiéramos de Darwin o Einstein. La compartieron los hebreos con los griegos, los asiáticos, los africanos, los americanos, todos los pueblos originarios.

— ¿Sabías — preguntó el Otro- que esa frase, "Hágase la luz", no estaba en el primer texto del Pentateuco, o la Torá? Harold Bloom y David Rosenberg han mostrado que ese texto original se atribuye a un autor llamado J (o Y, por el Yahvista) y que fue modificado más tarde por generaciones de revisores a los que se identifica con una letra: $\mathrm{E}$ (Elohísta), D (Deuteronomista), P (Padres), R (Redactor). ${ }^{14}$ Bloom infiere del relato básico que $\mathrm{J}$ pudo ser una mujer $\mathrm{y}$, como nunca ha sido tímido, agrega que pudo ser una integrante de la corte postsalomónica de Roboam. Al desacralizar el texto, Bloom da base a la idea de que $\mathrm{J}$

${ }^{13}$ Slavoj Žižek, Examined life. Philosophy in the streets, documental de Astra Taylor, 2008.

${ }^{14}$ Harold Bloom y David Rosenberg, El libro de $J$ (Barcelona: Interzona, 1995). 
escribió un relato acerca de un personaje literario superior, Yahvé, y las necesidades de la fe lo convirtieron en la palabra autoritaria de la Creación.

-Es curioso lo que dices — reflexionó el Uno-. Te respondería que, al menos en la tradición cristiana, la figura del Hijo, esa extraordinaria simbiosis de lo humano y lo divino, vino a equilibrar el lenguaje autoritario con el lenguaje de la salvación, y no se me ocurre un lenguaje más justo, igualitario, lo que en último término llamaríamos democrático.

—La levadura del mal y del bien — dijo el Otro, divertido y algo picado- Desde entonces, ese autoritario "Hágase la luz" se ha asociado también a la creación humana, especialmente la artística, con la metáfora del demiurgo...

- ¿Y no te parece - agregó el Uno- que las ideologías, estandartes del racionalismo, parten siempre de metáforas literarias con una carga similar, construcciones lingüísticas que procuran interpretar el mundo?

-No lo había pensado - dijo el Otro, descolocado-. Lo que veo es que ese impulso autoritario llega hasta nosotros en esa consigna según la cual "el lenguaje crea realidad". Es una linda idea literaria, muy cara al Pentateuco reescrito tanto como, digamos, a Borges. La modernidad la sacó de su significado literal para que más tarde deviniera en creación de realidad psicológica, social o política, pero siempre autoritaria. Alain Touraine nos ha recordado que el movimiento feminista fue pionero en demostrar que la forma autoritaria del lenguaje ha sido uno de los pilares de la discriminación sexista. ${ }^{15}$

—Debió agregar a los movimientos antirracistas... —añadió el Uno, con una sonrisa leve que al Otro le pareció una oblicua ironía-. Las ultrafeministas, en todo caso, nos tienen hablando de "chilenos y chilenas", que es una manera ruborizante de confundir el género como sexo con el género como categoría gramatical. La filóloga Maria Carme Junyent ha dicho que esta fiesta irreflexiva termina por ridiculizar a las mujeres: la bicicleta que pide ser bicicleto, o el lenguaje la lenguaja, por no hablar de otros precipicios. ¿Imaginas un discurso que empezara diciendo: "Señores hombres públicos, señoras mujeres públicas"?

${ }^{15}$ Alain Touraine, Un nuevo paradigma (Barcelona: Paidós, 2005). 
- No quería bromear, aunque me tientas — replicó el Otro-. Supongo que las ultrafeminatas, como las llama Arturo Pérez Reverte, parten de esa frase, "el lenguaje crea realidad". Yo la veo siempre más peligrosamente cerca de la política. La veo con fuerza en la propaganda y a veces en la publicidad. Quiero decir que todos los políticos y los amantes de la ingeniería social han llegado a creer que "el lenguaje crea realidad" con un fervor que hay que temer, porque al final del camino refulge otra luz, la del poder puro y duro. El visionario Lewis Carroll puso en boca de Humpty Dumpty esta afirmación que sobrevuela todo el siglo XX: "Cuando yo uso una palabra quiere decir lo que yo quiero que diga... ni más ni menos". Alicia le discute si una palabra puede ser ocupada con diversos significados y Humpty Dumpty responde, taxativo: "El problema es quién manda". ${ }^{16} \mathrm{El}$ significado es el poder. El mensaje es el masaje.

El Uno rió, aceptando el juego. Y agregó:

- Te cambio esas frases por las de otro insidioso, el judío Shylock: “¿Acaso no sangramos si nos pinchan?... ¿Acaso no morimos si nos envenenan?"17 El significado es la igualdad. El mensaje es el pasaje.

-Eres un poco tramposo - dijo el Otro- Con Shakespeare me rindo.

- No, no era una trampa. Sólo era una manera de decirte que uno de los cínicos más grandes de la historia pudo pronunciar una de las frases más nobles jamás concebidas. Eso es el lenguaje: una fuerza redentora que no se compara con nada. "Padre, padre, ¿por qué me has abandonado?". ¿No está toda la historia de la humanidad comprimida en esas siete palabras castellanas, apenas cuatro en arameo y en hebreo (Eli, Eli, lema 'sěbaqtani)? Así como tú ves una tradición autoritaria en la palabra, yo veo al mismo tiempo una tradición salvífica o, en la esfera que tú prefieres, estética, una función que no consiste en fundar el mundo, sino en describirlo, comprenderlo, aprehenderlo. Es la función eminente, el don apacible, si me permites usar mal ese gran título de Sholojov. Por cada Goebbels han existido centenares de poetas libres; por cada Thomas Dixon han florecido las palabras contra el racismo;

${ }^{16}$ Debo esta idea a una gran escritora española: Belén Gopegui, Rompiendo algo (Santiago: Ediciones Universidad Diego Portales, 2014).

17 William Shakespeare, El mercader de Venecia (Madrid: Alianza Editorial, 2005). 
por cada ayatola Jomeini hay millares de escritores que desafían el oscurantismo.

- Bueno - dijo el Otro, con un asomo de cansancio-, comprendo que no podemos escapar de estas dos tradiciones que hemos descrito. Pero, ¿qué nos dice esto acerca del lenguaje público, el del periodismo?

- Ya sabes - dijo el Uno-, el lenguaje del periodismo nos proporciona algunas de nuestras mejores sonrisas. En Chile, la gente nunca muere, siempre fallece. Los acusados de delitos suelen ser sujetos en vez de personas y si pasas de los cincuenta y te caes en la calle bien puedes ser considerado un anciano. El agua pierde su estado líquido para ser un vital elemento, todo incendio es un siniestro y todo problema de tránsito es un colapso. El ministro ya no hace una declaración, sino que tiene una vocería. Las cosas no se sitúan, se posicionan. Los cuerpos perdidos no logran ser rescatados. He oído de fallecidos que no lograron no fallecer.

- Yo también me río — admitió el Otro-, pero hay un aspecto que me molesta: la sensación de inconsciencia, de alienación del lenguaje. Por lo que sé, un periodista que dedica un minuto a pensar en lo que dice hace toda la diferencia. $Y$ eso es porque todos los periodistas entendemos que una palabra no es igual a otra, que cada término implica una elección, cada adjetivo una selección. No hay inocencia posible. Nadie es tan tonto para defender tal inocencia, pero todos los días incurrimos en la irreflexión, hasta que una tarde de nuevo nos pillarán volando bajo los viejos de mierda y las ratas que se matan. Tengo poca simpatía por el periodismo de denuncia, ése que anda capturando rateros de poca monta y ni se acerca a los grandes guarenes, pero me gustaría ver un periodismo que cazara los brotes de la intolerancia, como un buen gato, apenas los sintiera aparecer. Lo digo sin esperanza. No me gusta el periodismo como policía.

-No seas tan pesimista — propuso el Uno-. Por encima de sus flaquezas idiomáticas, el periodismo suele cultivar la democracia, hasta que la democracia deja de cultivarse a sí misma.

- Me consuelas bien poco - ironizó el Otro-. ¿Podrías decirme una frase, una sola, como el justo de Sodoma, que representara el lenguaje democrático en el periodismo de nuestros tiempos?

-Ah, sí. Debe haber muchas, pero tengo la mía. Es la siguiente: "El País con la Constitución”. Fue el titular con que amaneció el diario 
español El País, el 24 de febrero de 1981, después de que el coronel Tejero amenazara con conculcar la democracia ocupando el congreso. Fue un golpe de genio y ambigüedad, o de ambigüedad y por eso de genio: el diario mezclaba su posición con la de su público, el país unido con $E l$ País y ambos con la legalidad que debía poner coto a una insurrección ilegítima. Periodismo y moral pública.

- Te gustan las paradojas - comentó el Otro-. Yo me quedo con el inmenso titular de France Soir, de 1985: "Orson Welles est mort". Por una vez, por una sepulcral vez, el arte sobre todo. Pero bien: ¿y si El País hubiese titulado ese día: "A parar el golpe fascista"?

- Se habría equivocado - sentenció el Uno.

- Un paso en falso en el lenguaje — dijo el Otro, casi para sí mismo-. El lenguaje es el enemigo. Uno escribe con el enemigo.

-No y sí - aclaró, sin aclarar, el Uno-. El enemigo somos nosotros. Alguien lo dijo, ¿no?

- Teilhard de Chardin, creo. Jesuita y ortogenista, ya me dirás tú. Sartre le salió al paso: "El infierno son los demás". ¿Con qué nos quedamos los periodistas?

- Con los dos - dijo el Uno-. Yo prefiero al primero, pero si pienso en las tiranías, no puedo rechazar al segundo. Hay un momento en que somos culpables, otro en que somos inocentes. Sólo la conciencia nos pone a uno u otro lado de esa triste frontera. Y puesto que andamos muy ocupados para regalarle tiempo a la tristeza, propongo que le entreguemos esos minutos a la conciencia. No tengo otro consejo para ofrecer. Salud, compañero.

- Salud — dijo el Otro- Esta conversación me recuerda, viciosamente, las del Stalker, ${ }^{18}$ con esos tres personajes que buscan alguna verdad en un espacio donde todo ha sido contaminado. La verdad que desean es una justificación de sí mismos, pero también una idea del futuro posible. En fin... Sólo te pregunto una cosa más: ¿es posible un lenguaje democrático?

Un delgado sonido le hizo entender que el Uno ya dormitaba. El Otro advirtió entonces que sobre la tarde caía una llovizna sucia de esmog. Se marchó sin saber si habían encontrado la movediza encrucijada entre el lenguaje y la democracia. En los siguientes treinta años, por de-

${ }^{18}$ Andrei Tarkovski, Stalker, largometraje, 1979. 
bajo del pavimento y de la muerte, el Uno y el Otro siguieron debatiendo sobre lo mismo en el silencio de los mediodías, y siempre terminaban perturbados y riéndose. Alguno de los dos murió, alguno sobrevivió para recordarlo en alguna tarde como ésta. EP 